\title{
Experimental Study on the effect of Crosswind on a Container Train with Different Load Configurations
}

\author{
S. Giappino, S. Melzi, G. Tomasini and M. Villani \\ Department of Mechanical Engineering \\ Politecnico di Milano, Italy
}

\begin{abstract}
Increasing the operating speed of freight trains constitutes an important factor to improve rail transportation competitiveness towards road transportation. As a drawback, higher speeds may pose safety issues associated also with crosswind effects. The design of a freight wagon is usually characterized by wide sections with a high drag coefficient, which likely increases the risk of derailment or rollover. Also train-set composition may play a role in affecting the running safety, especially when a series of empty vehicles is followed by a loaded one, which can be found to be completely exposed to wind action. The paper investigates the aerodynamic responses of a freight train, for intermodal transportation, to crosswind using a series of wind tunnel tests. A 1:20 model of a freight train composed by an engine and two flat-car vehicles was instrumented with force balances to measure the aerodynamic coefficient on each vehicle and each container. Aerodynamic coefficient as function of yaw angle between wind and train-set are eventually presented.
\end{abstract}

Keywords: freight train, crosswind, container, aerodynamic coefficients.

\section{Introduction}

The investigation of railway vehicles aerodynamics is of great importance both for economic and safety reasons; in fact, the knowledge of the wind loads acting on a convoy allows on the one hand to address energy consumption issues [1], on the other hand to study the aerodynamic stability of the train. In this field, the major interest was aimed at passenger trains as they travel at higher speed and are much lightweight with respect to freight trains [2]. In recent years, environmental concerns and cost savings opportunities (at least for long-medium distances), increased the interest towards goods transportation by means of freight trains. However, simpler logistics management and door to door operation, still represent factors that make road transportation strongly attractive. For this reasons, increasing operating speed 
of freight trains can improve the competitiveness of rail transportation overcoming part of its logistics limits. Freight train speed is being continuously and gradually increased so that the travel time on long and medium distances could be comparable to that of ordinary passenger trains.

This poses a series of safety issues associated with the enhanced dynamics of the trainset and of the single vehicle [3] but, since a wagon with wide high-drag surfaces can reach speeds up to $160 \mathrm{~km} / \mathrm{h}$, also crosswind effect has to be considered [4]. In particular, while in passenger trains wagons are in tight composition and the front section of a vehicle is not directly exposed to wind, in freight trains a significant gap between adjacent vehicles is present. When considering a trainset made up of flat car vehicles, it is also possible to find empty vehicles followed by a loaded one (usually carrying a container), which therefore results strongly subjected to aerodynamic forces.

The necessity to operate goods trains at higher speed has thus given an impulse to the study of the aerodynamics of this kind of vehicles with a particular focus on the possibility to optimize the load configuration on convoy used for intermodal transport (container trains). The importance of this investigation was also remarked by the evidence of some crosswind accidents, which involved empty containers being blown away by the wind [5].

In this work the aerodynamics of freight train for intermodal transport was investigated experimentally by means of wind tunnel tests. A 1:20 model of a trainset made up of three vehicles ( 1 engine and 2 flat car wagons) was analysed considering different load configurations and measuring the forces and moments generated by relative wind on each single wagon and on each single container. Aerodynamic coefficients were identified for yaw angles between wind and train-set ranging from 0 to $90^{\circ}$. The identified coefficients will be the base to the calculation of the Characteristic Wind Curves which allow to define the risk of overturning associated to a vehicle for specific wind and running speeds [4][6][7][8]. The obtained results will be discussed also with reference to the available literature data, based on wind tunnel tests or numerical simulations [10]

The research activity presented in this paper, is part of SIFEG project funded by the Italian Ministry of Economic Development (MISE).

\section{Wind tunnel tests}

\subsection{Test facility characteristics}

Wind tunnel tests have been performed on a 1:20 scale model of a freight train (Figure 1). The convoy has been tested with a flat ground scenario (without ballast and rails), which is one of the reference scenarios described in the TSI 232/2008 standard [7]. The train is composed by 3 vehicles: one front engine and two freight carriages instrumented to measure the aerodynamic forces. Tests have been performed in the high-speed section of the Politecnico di Milano wind tunnel (CIRIVE) in order to determine the aerodynamic coefficients of the considered vehicle in agreement with the requirements of TSI 232/2008. 
The wind tunnel is a closed circuit facility in vertical arrangement having two test sections, a $4 \times 4$ high speed low turbulence and a 14x4 low speed boundary layer test section. Tests were carried out in the High-Speed test section, whose characteristics are listed in Table 1 . The test chamber is provided with a turntable (diameter $2.5 \mathrm{~m}$ ) allowing to vary the incidence angle.

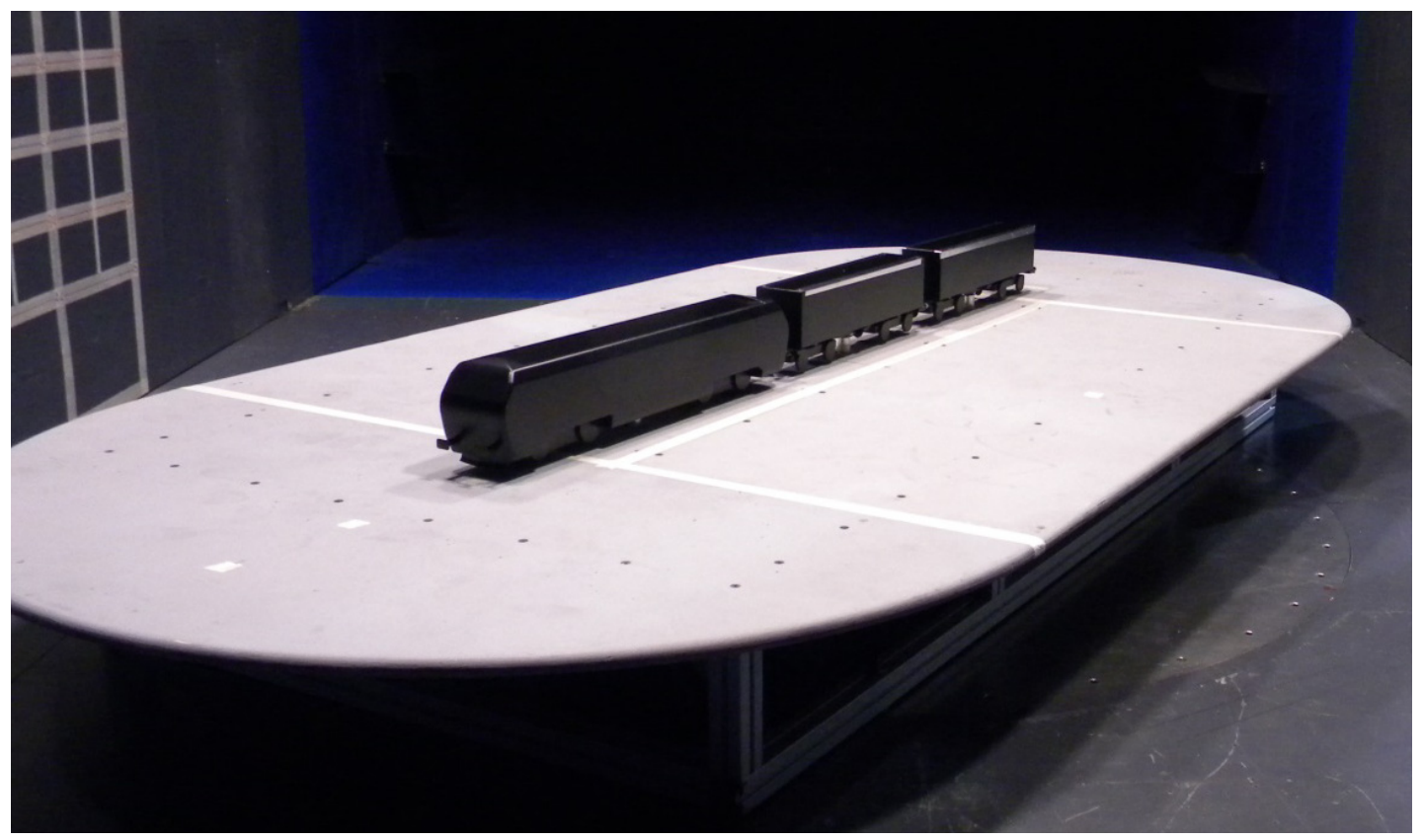

Figure 1: 1:20 scaled model of the convoy in the High-Speed test section of the Politecnico di Milano Wind Tunnel

\begin{tabular}{cccc}
\hline Size & Maximum speed & $\Delta \mathbf{U} / \mathbf{U}$ & $\mathbf{I}$ \\
\hline $4 \times 4$ & $55 \mathrm{~m} / \mathrm{s}$ & $< \pm 0.2 \%$ & $<0.1 \%$ \\
\hline
\end{tabular}

Table 1: main characteristics of the high-speed test section.

In the high-speed test section tests have been performed in conditions of low turbulence, with different Reynolds numbers, in agreement with the requirements of TSI 232/2008 $\left(\mathrm{Tu}_{\mathrm{x}} \leq 2.5 \%\right.$, par. G.5.1.2.2, [7]).

\subsubsection{Flow characteristics}

The turbulence level of the test section is equal to $0.1 \%$; this value is lower than the maximum one allowed by TSI $232 / 2008$ [7]. The boundary layer thickness, $\delta 95 \%$, is approximately $61 \mathrm{~mm}$ from the top of the flat ground (about $45 \mathrm{~mm}$ from the top of 
the rail) corresponding to nearly $22 \%$ the vehicle height in agreement with the TSI [7], G.5.1.2.3 .

The wind tunnel tests in the High-Speed test section have been performed with different wind speeds ranged between $\mathrm{V}=10 \mathrm{~m} / \mathrm{s}$ and $\mathrm{V}=50 \mathrm{~m} / \mathrm{s}$. The corresponding Reynolds number is calculated as:

$$
\operatorname{Re}=\frac{V^{*} D}{v}
$$

where the characteristic dimension $\mathrm{D}$ is the reference length $(\mathrm{D}=3 \mathrm{~m}$ at real scale) while $v$ is the air cinematic viscosity $\left(v=1.5 * 10-5\left[\mathrm{~m}^{2} / \mathrm{s}\right]\right)$. The maximum $\operatorname{Re}$ number is equal to 500000 .

According to the TSI 232/2008 (par. G 5.1.2.4 [7]), the Reynolds number independency is investigated in the range $0.2 \mathrm{Re}_{\max } \div \mathrm{Re}_{\max }$.

The maximum blockage ratio $\mathrm{x}_{\mathrm{B}}$ has to be defined at a yaw angle of $30^{\circ}$ (par. $\mathrm{G}$ 5.1.2.1, [7]). It is calculated as the ratio of the total modelled configuration (train model + flat ground) projected side area to the wind tunnel cross section. For the considered configuration, this parameter is equal to $4.85 \%$. In agreement with the requirements of [7], the blockage ratio is smaller than $10 \%$. According to the normative, for closed test section with this value of blockage ratio no blockage correction is needed.

\subsection{Trainset model}

As already mentioned, the trainset tested in the wind tunnel is made up of one front engine and two wagons. The focus of the research consists on measuring the global aerodynamic forces and moments acting on each wagon and on each container individually. Therefore, particular care was taken when designing the model of the wagons, so that miniaturized force balances could be mounted on the flat car allowing measurement of aerodynamic forces and moments on the container.

The models of the engine and the containers have been built with machine-cut polyurethane model boards, while the flat-car are made of aluminium. Each vehicle is equipped with a steel pole (Figure 2) providing the constraint to the scenario; as far as the wagons is concerned, the steel poles are linked to two dynamometric 6components force balances; the engine is instead directly fasten on the scenario. The stiffness mounting system is high enough to ensure that the dynamics of the model is negligible. The constraints allow to adjust both vertically and longitudinally the position of the three vehicles.

Figure 3 shows the three vehicles, with particular focus on the model of a wagon; as can be noticed, the container can be easily mounted on the balance fixed on the flat car.

Table 1 resumes the three main dimensions, length, width and height of the full scale vehicles and the nominal dimensions for the 1:20 scaled model. 


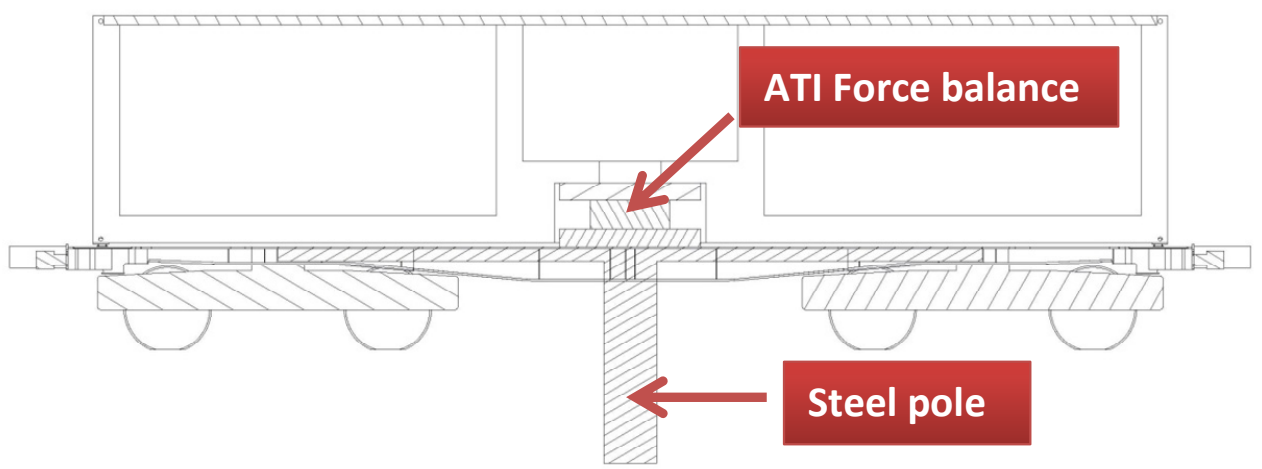

(a)

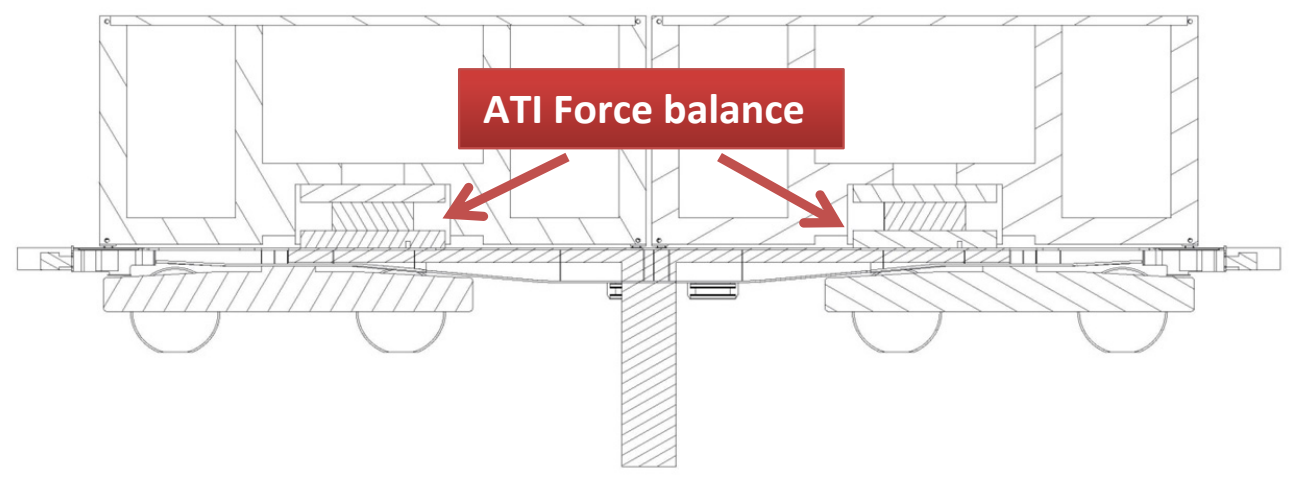

(b)

Figure 2: Connections of the miniaturized force balance for the model of $40 \mathrm{ft}$ container (a) and for the two models of $20 \mathrm{ft}$ containers (b).

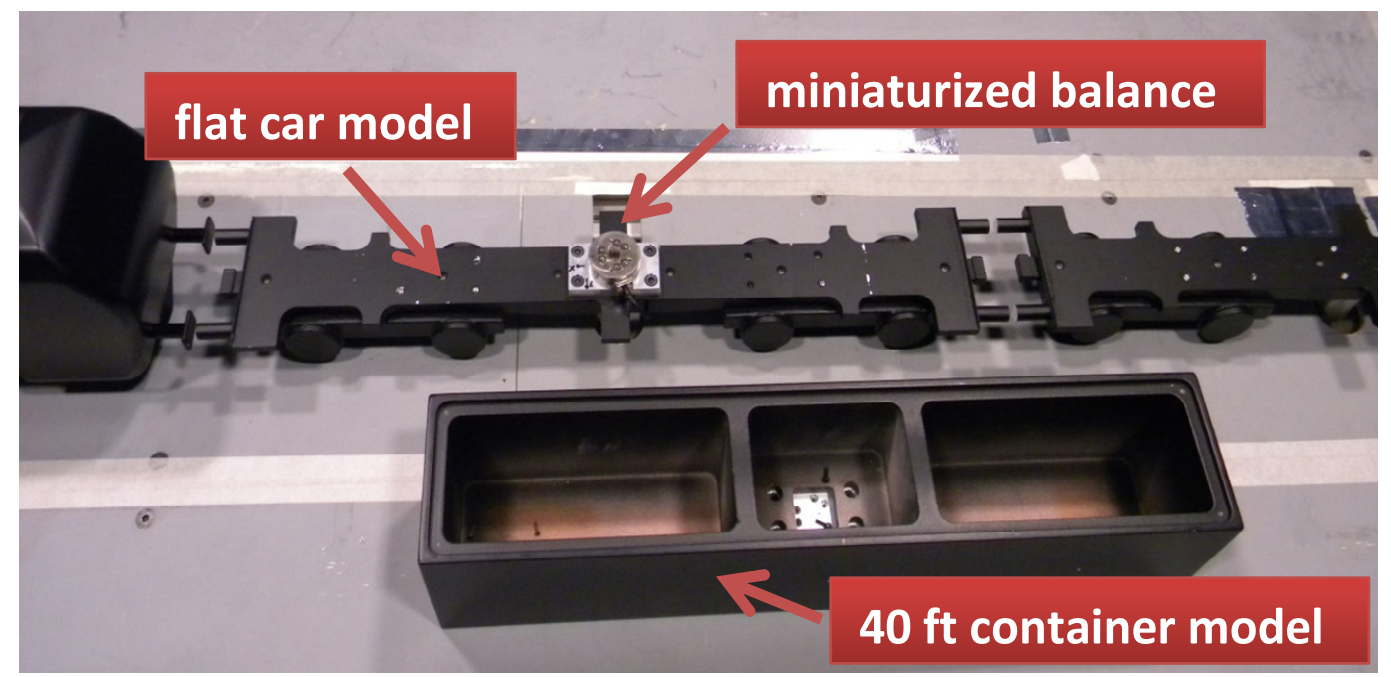

Figure 3: Assembly of the experimental set up. 


\begin{tabular}{|ccc|}
\hline & $\begin{array}{c}\text { Real values } \\
{[\mathbf{m m}]}\end{array}$ & $\begin{array}{c}\mathbf{1 / 2 0} \text { scale } \\
\text { nominal values [mm] }\end{array}$ \\
\hline Engine length & 18480 & 924 \\
\hline Engine width & 2920 & 146 \\
\hline Engine height & 3620 & 181 \\
\hline Wagon length & 12800 & 640 \\
\hline Wagon width & 2438 & 121.9 \\
\hline Wagon height & 3792 & 189.6 \\
\hline
\end{tabular}

Table 2: Overall dimensions of the real vehicles and corresponding models.

\subsubsection{Aerodynamic forces measurement}

In order to measure the global aerodynamic forces acting on the vehicles, two 6components industrial RUAG model 192 force balances have been connected below the two freight carriages of the convoy. Figure 4 shows the connection system between balance and model. The force balance is connected to the train model by means of a steel pole in the center of the underbody. The stiffness of the connection ensures that the aerodynamic forces that arise on all the external surfaces of the vehicle model are transferred only to the dynamometric balance.

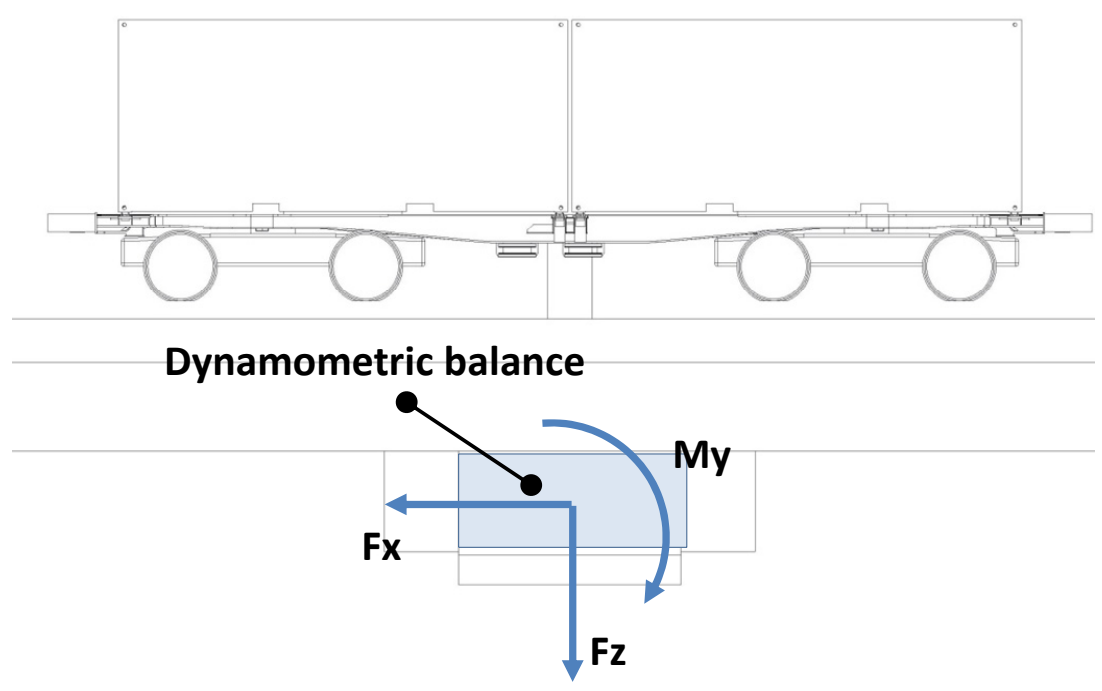

Figure 4: Scheme of connection between the scale model and the dynamometric balance and corresponding reference systems.

At the interface between each container and the flat car a miniaturized sixcomponents force balance (ATI model mini45) is interposed (Figure 5); this allows to measure all the aerodynamic forces and moments exerted on the container alone. Each flat car is designed so that balances can be mounted in three position: a single balance at the center of a $40 \mathrm{ft}$ container and two balances at the center of $220 \mathrm{ft}$ 
containers. As shown in Figure 2, models of the containers are provided with enough inner room to host the balance.

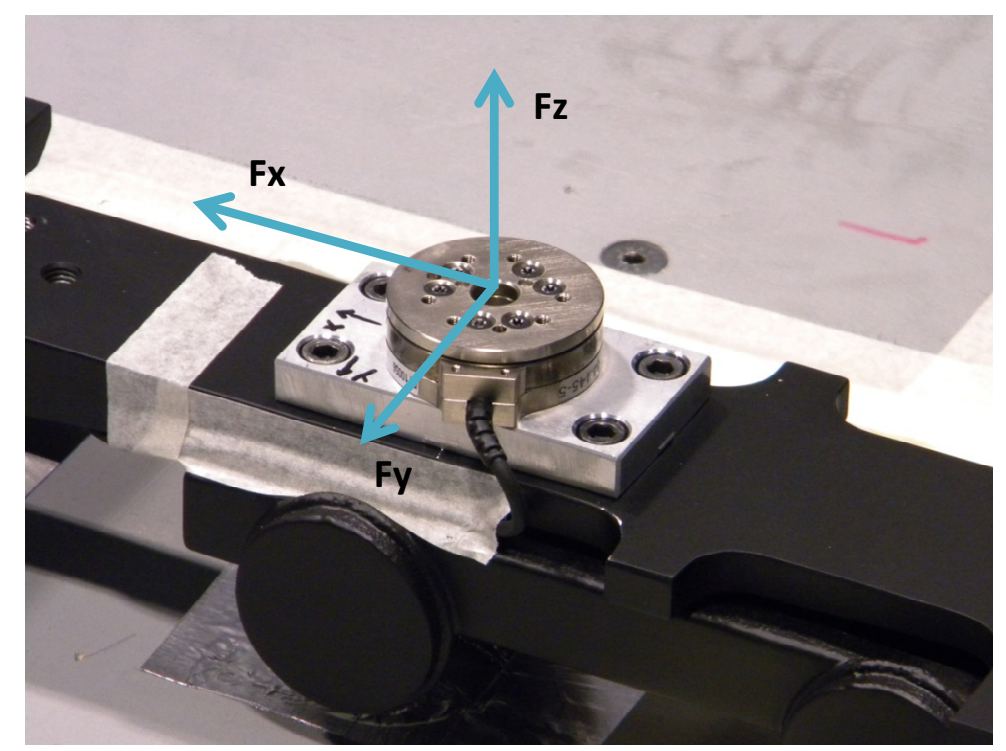

Figure 5: detail of the miniaturized ATI six-components force balance.

\subsubsection{Aerodynamic force coefficients}

According to the CEN standard [8], the non-dimensional coefficients are defined as follows:

$$
\begin{aligned}
C_{F_{i}} & =\frac{F_{i}}{1 / 2 \rho A \bar{U}^{2}} \\
C_{M_{i}} & =\frac{M_{i}}{1 / 2 \rho A h \bar{U}^{2}}
\end{aligned}
$$

where $\mathrm{F}_{\mathrm{i}}(\mathrm{i}=\mathrm{x}, \mathrm{y}, \mathrm{z})$ are the aerodynamic force components in the train reference system and $\mathrm{M}_{\mathrm{i}}(\mathrm{i}=\mathrm{x}, \mathrm{y}, \mathrm{z})$ are the corresponding moments. In equation $1, \rho$ is the air density, $\bar{U}^{2}$ is the mean square value of the wind speed, $h$ is equal to $3 \mathrm{~m}$ (full scale), and $A$ is a standard reference surface which is equal to $10 \mathrm{~m}^{2}$ (full scale).

All the coefficients are evaluated on the midpoint of the track at top of the rail (see Figure 2), while the rolling moment is calculated both with respect to the middle of the track $\left(\mathrm{CMx}_{\mathrm{M}}\right)$ and with respect to the lee rail ( $\mathrm{CMx}_{\mathrm{Mx}}$ ).

In this study the same normalization has been also used to calculate the force coefficients on the containers alone. In this case the moments are calculated with respect to the point in the center of the container bottom side. The use of a fixed reference area is helpful since the comparison of the force coefficients in different layouts means exactly a comparison in terms of wind force (all the wind forces have been normalized with the same area). 


\subsection{Test conditions}

\subsubsection{Test scenario}

The infrastructure scenario is the flat ground one (TSI [7]). It has been simulated by a splitter plate in order to have a block profile of the mean wind speed (see Par. 2.1). The splitter plate is supported by an aluminium platform and the top of the splitter plate is placed at a height of $0.350 \mathrm{~m}$ from the wind tunnel floor. Figure 6 shows the configuration of testing within the walls of the high-speed test section.

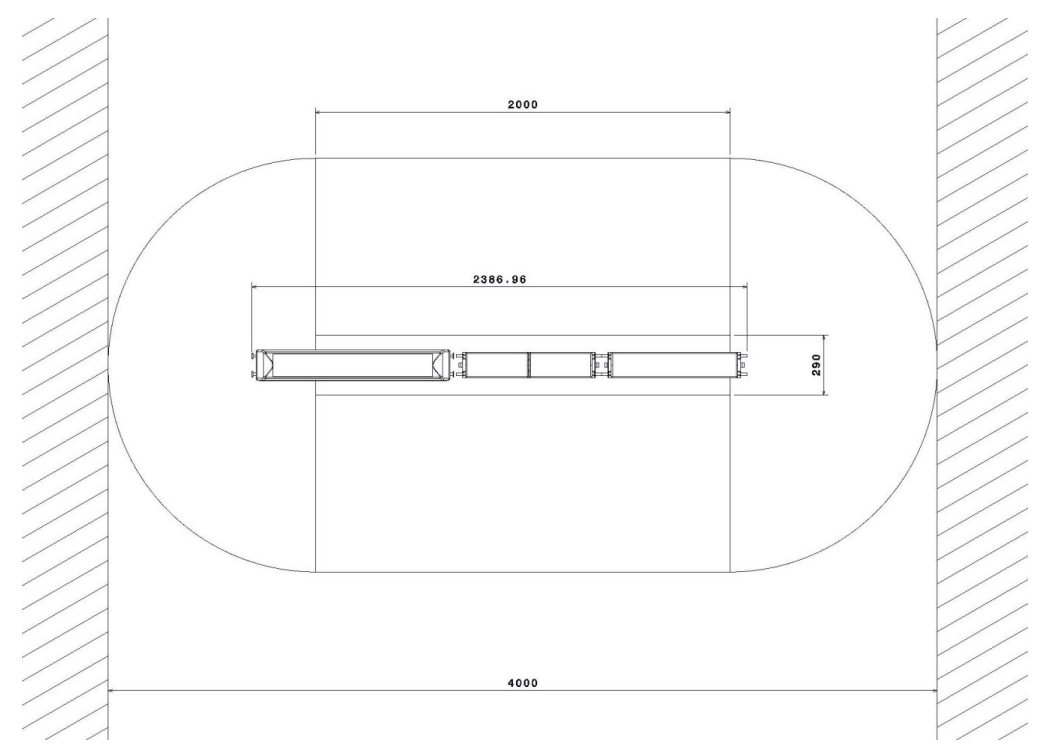

Figure 6: Drawing of the scenario within the high speed test room.

Figure 7 shows the assembly of the train over the scenario. The distance between the lower part of the train and the top of the ballast is represented in the detail A while the gap between the two vehicles is represented in the detail B.

About the detail $\mathrm{B}$, it is possible to note that the actual interconnection realised between the wagons is different with respect to the original drawings. This modification has been introduced in order to avoid the contact between the two vehicles. Any contact in fact would affect the force balance measures.

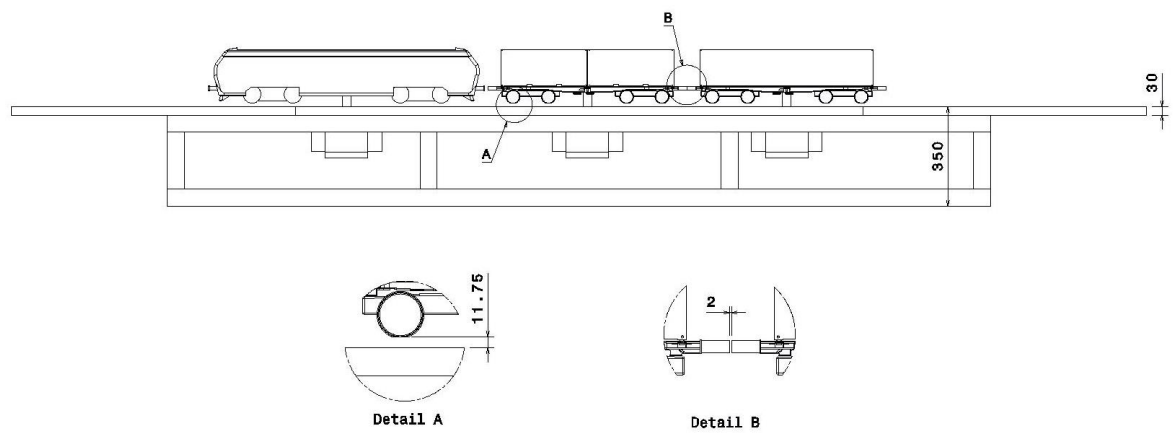

Figure 7: Position of the convoy on the scenario. Distance between the vehicles (detail B) and distance flatground - TOR (detail A). 


\subsubsection{Trainset layout}

During the experimental campaign eight load layouts have been tested, varying the size and the position of the gaps between the containers on the wagons, ranging from an unloaded condition to a full-load one (see Table 3 ).

\begin{tabular}{cccc}
\hline Layout & $\mathbf{1}^{\text {st }}$ wagon & $\mathbf{2}^{\text {nd }}$ wagon & \multicolumn{2}{c}{ Scheme } \\
\hline 1 & $40 \mathrm{ft}$ container & $40 \mathrm{ft}$ container & $\frac{1}{20}$ \\
\hline 2 & $40 \mathrm{ft}$ container & $120 \mathrm{ft}$ container rear & $\frac{1}{2}$ \\
\hline 3 & $40 \mathrm{ft}$ container & $220 \mathrm{ft}$ containers & $\mathbf{2}$ \\
\hline 4 & empty & $220 \mathrm{ft}$ containers & $\mathbf{1}$ \\
\hline 5 & empty & $120 \mathrm{ft}$ container rear & $\mathbf{1}$ \\
\hline 6 & empty & $40 \mathrm{ft}$ container & $\mathbf{2}$ \\
\hline 7 & $40 \mathrm{ft}$ container & empty & $\mathbf{2}$ \\
\hline 8 & empty & empty & $\mathbf{2}$ \\
\hline
\end{tabular}

Table 3: Trainset load distribution layouts.

\section{Experimentation results}

Lateral wind loads are important both for the train stability but also for the anchorage of the container itself. The two topics are investigated separately in the two following paragraphs.

\subsection{Overall wind loads on wagons}

The different trainset layouts are compared in terms of aerodynamic coefficients: to investigate the crosswind effects the most important ones are the moment coefficient with respect to the longitudinal axis $C_{M x}$, the lateral force coefficient $C_{F y}$ and the vertical force coefficient $C_{F z}$. More often it is also considered the rolling moment coefficient with respect to the leeward rail $C_{M x, \text { lee }}$ [9][11]. In particular this last one is used in the simplified method for the evaluation of the rollover risk in the European standard EN 14067-6 [8]. Using this approach the calculation of the characteristic wind speed is based on the moment of equilibrium towards the leeward rail.

Figure 8 shows the aerodynamic coefficients on the first wagon: for simplicity purposes we show only the most significant layouts in the graphs. As expected the large difference is due to the presence/absence of the container on the flat car ( $L 1$ versus $L 8$ ). The worst configuration is the $L 1$ that is the train fully loaded. We found a small reduction both in the lateral force and in the rolling moment when the second wagon is empty ( $L 7)$. The maximum moment coefficient is found at a wind angle of $50 \mathrm{deg}$. 
A different behaviour is visible in the vertical force (Figure $8 \mathrm{~b}$ ) where at small angles the lift force is significantly higher with the container while for $\beta>60$ deg the vertical force with and without the container is very similar.

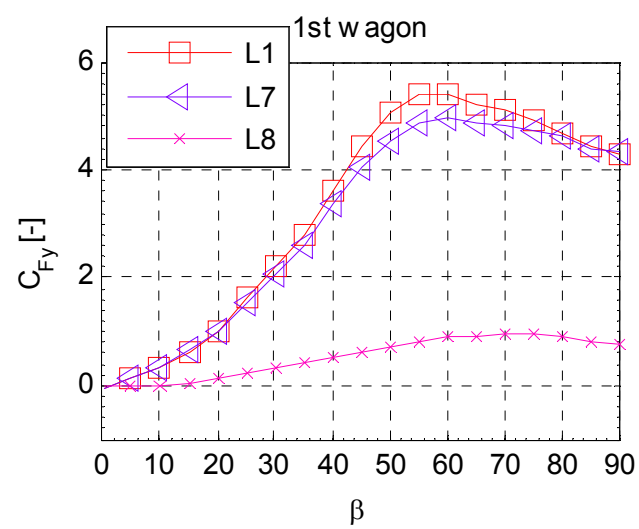

(a)

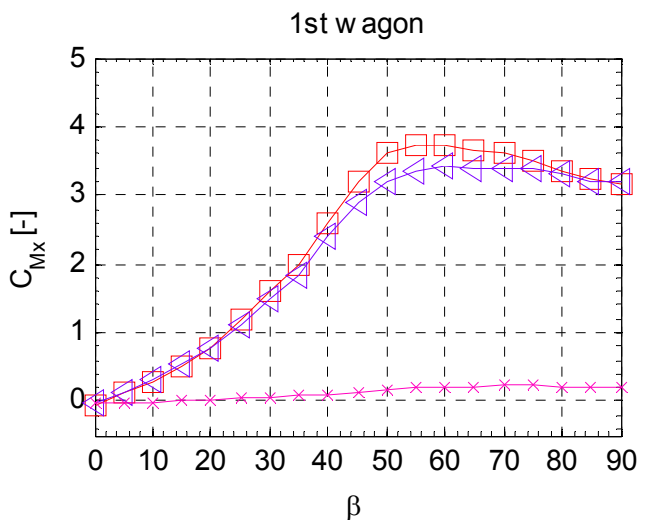

(c)

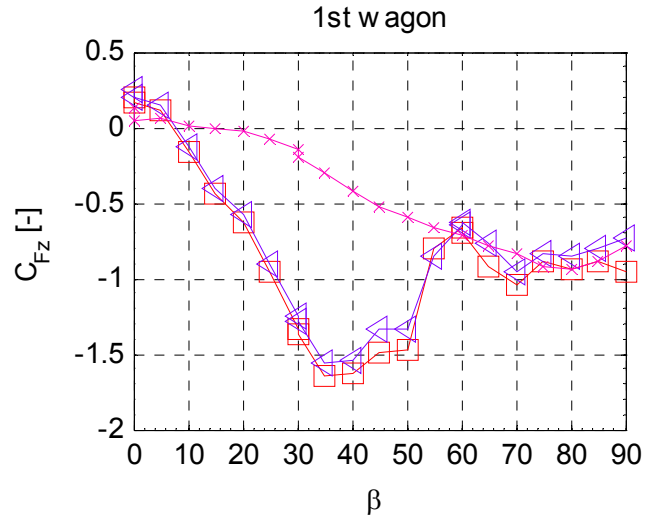

(b)

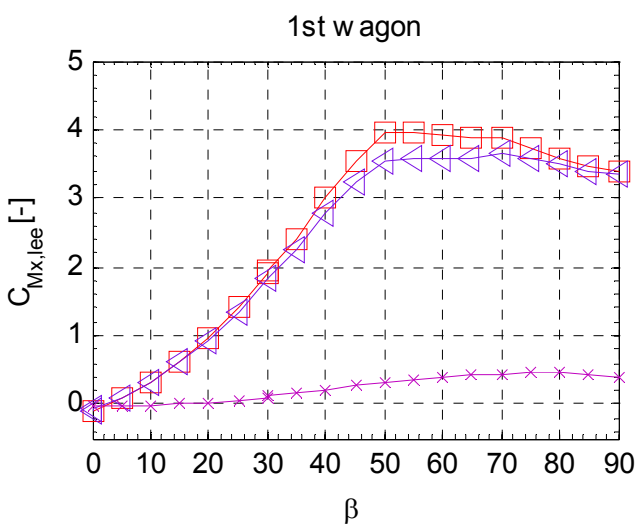

(d)

Figure 8: Overall aerodynamic force coefficients on the first wagon: $\mathrm{C}_{\mathrm{Fy}}(\mathrm{a}), \mathrm{C}_{\mathrm{Fz}}$ (b), $\mathrm{C}_{\mathrm{Mx}}(\mathrm{c})$ and $\mathrm{C}_{\text {Mxlee }}(\mathrm{d})$.

We identify a different behavior in the second wagon (Figure 9). Considering the lee rail rolling moment coefficient the worst condition is identified in layout 6 , that is an empty first wagon followed by a fully loaded one. The maximum value is slightly lower than the one on the first vehicle and it takes place at 90 degrees. We observe also that $L 6$ is higher than $L 1$ at the small angles. Since the wind angle in the wind tunnel tests represents the relative wind angle in real conditions, due to the combination of the train speed and the wind speed, the most important angles in the evaluation of the rollover risk are the ones below 50 degrees. We compare the worst case on wagon 1 and the worst case on wagon 2 in Figure 10. It comes out that at small angles the forces on a wagon that follows and empty one can be up to $20 \%$ higher than in case of a fully loaded train. We found no differences on the overall loads comparing the case of a single $40 \mathrm{ft}$ container with respect to the case of two 20 $\mathrm{ft}$ ones: the small gap between the two container has negligible effects on the wagon aerodynamics. 


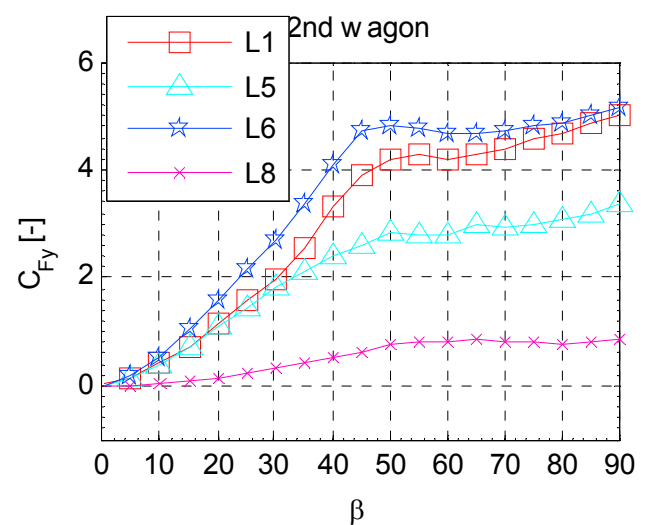

(a)

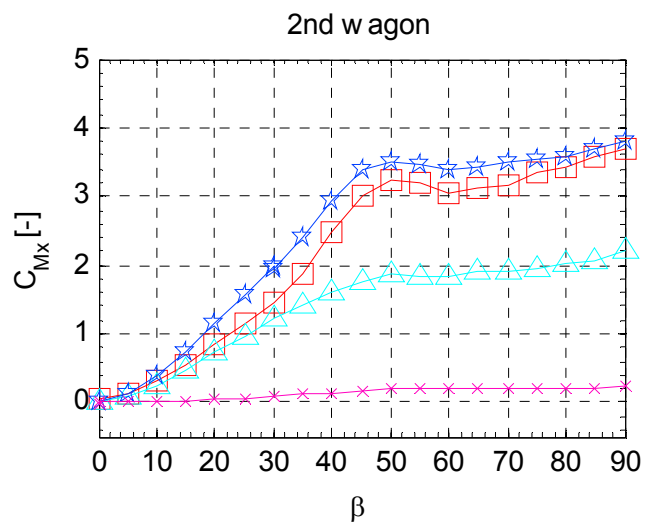

(c)

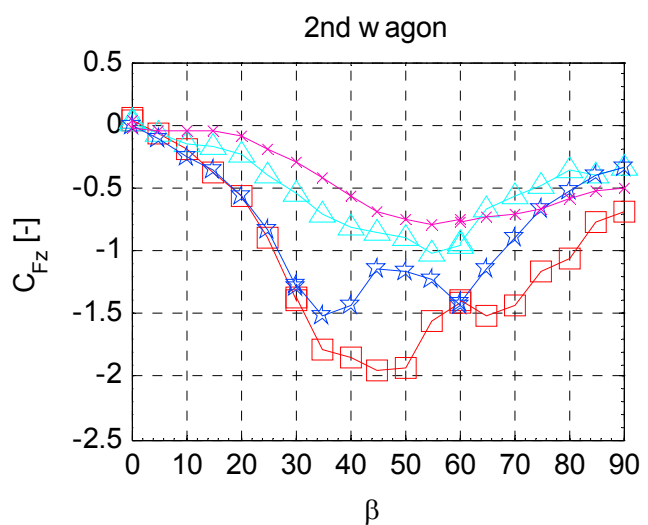

(b)

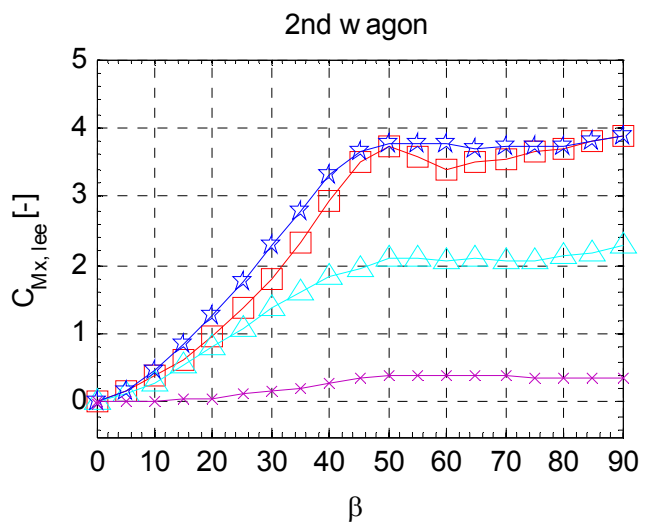

(d)

Figure 9: Overall aerodynamic force coefficients on the second wagon: $\mathrm{C}_{\mathrm{Fy}}(\mathrm{a}), \mathrm{C}_{\mathrm{Fz}}$ (b), $\mathrm{C}_{\mathrm{Mx}}(\mathrm{c})$ and $\mathrm{C}_{\text {Mxlee }}(\mathrm{d})$.

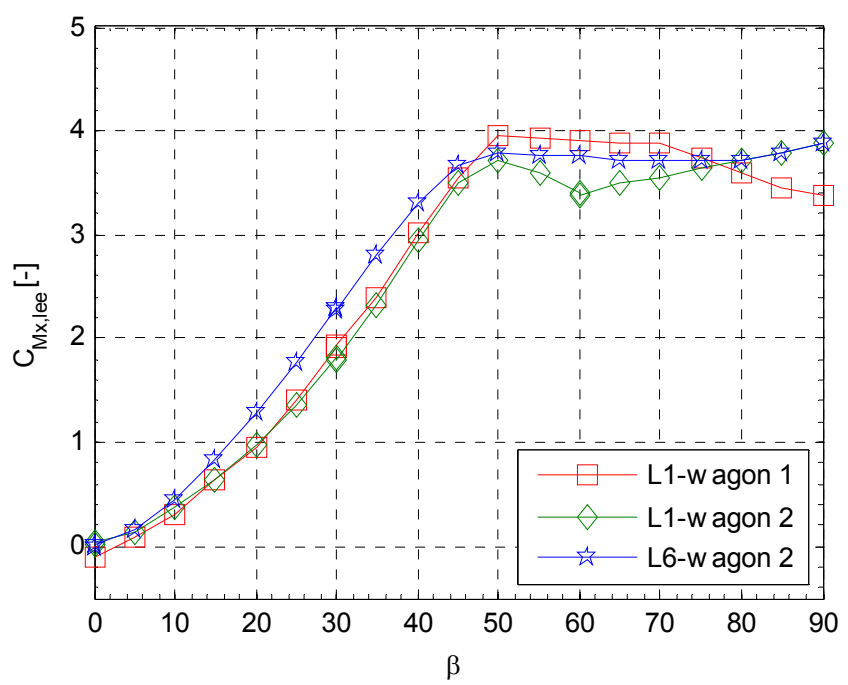

Figure 10: Lee rail rolling moment coefficient. Comparison between the worst cases on the two wagons 


\subsection{Wind loads on containers}

In Figure 11 we focus the attention on the aerodynamic loads on the container only, in case of a long one $(40 \mathrm{ft})$. The graphs shows the aerodynamic coefficients in the different layouts and depending on the wagon where the container is located (Figure 11d). Since the major contribution to the lateral force is due to the wind force on the container and not on the flat car we draw now conclusions that are similar to the previous analysis. In fact also considering the container only the maximum load condition is in a fully loaded train (L1 - Pos A), but if we limit the analysis to the small angles a container that follows an empty flat car experiences the highest forces (L6-Pos B).

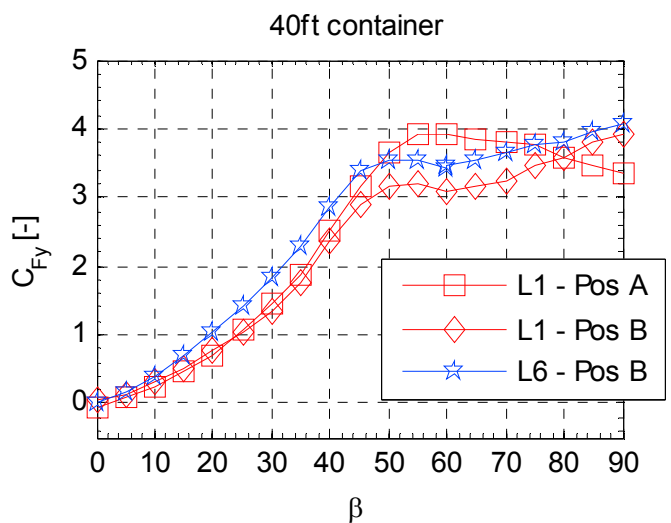

(a)

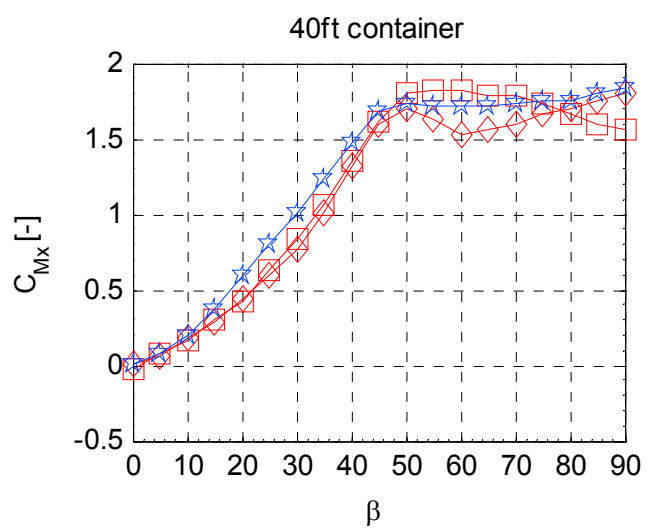

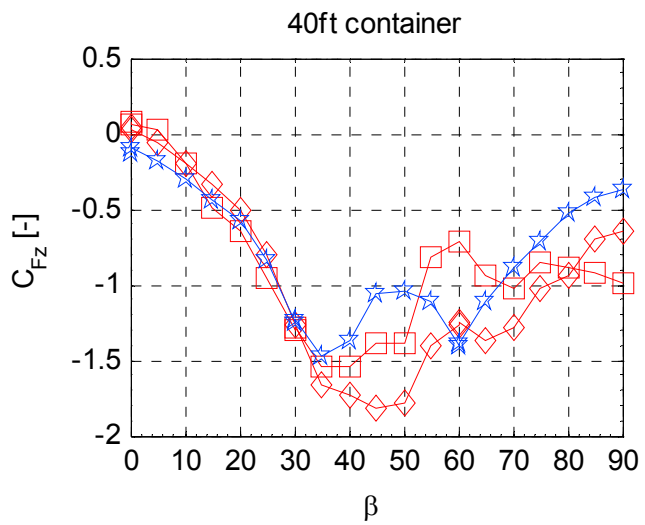

(b)

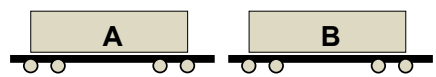

(c)

Figure 11: Aerodynamic force coefficients on the $40 \mathrm{ft}$ container: $\mathrm{C}_{\mathrm{Fy}}(\mathrm{a}), \mathrm{C}_{\mathrm{Fz}}(\mathrm{b})$, and $\mathrm{C}_{\mathrm{Mx}}(\mathrm{c})$

Figure 12 shows the force coefficients on the small container $(20 \mathrm{ft})$. Of course, due to the lateral surface that is halved the overall forces are significantly lower than the ones on the $40 \mathrm{ft}$ container. If we consider a fully loaded train the second container on the wagon carries higher loads than the first one (L3 - Pos C versus L3 Pos B). However if we limit the analysis to the small angles also a small container that follows an empty flat car experiences the highest forces (L4 - Pos B and L5 Pos C). 


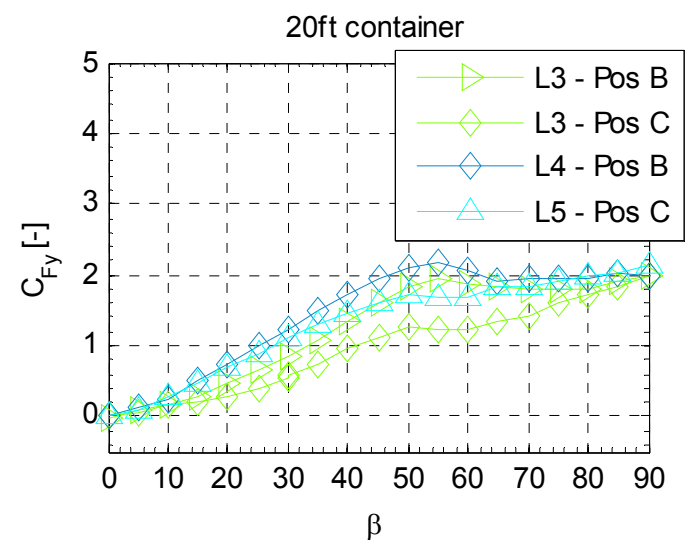

(a)

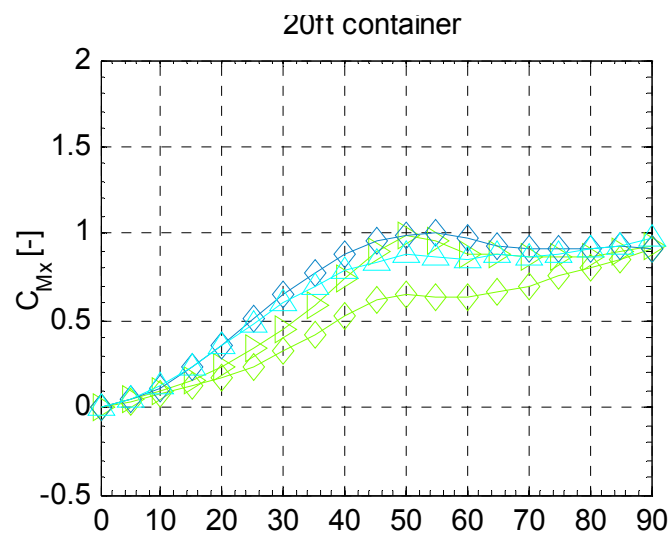

(c)

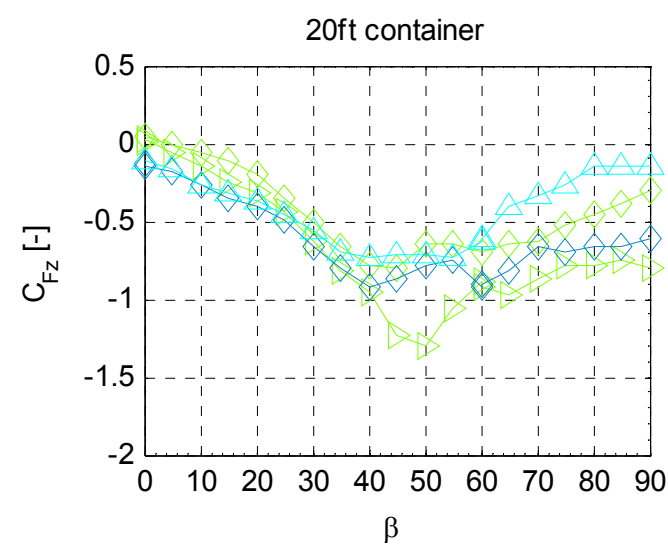

(b)

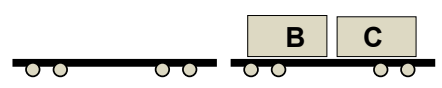

Figure 12: Aerodynamic force coefficients on the $20 \mathrm{ft}$ container: $\mathrm{C}_{\mathrm{Fy}}(\mathrm{a}), \mathrm{C}_{\mathrm{Fz}}(\mathrm{b})$, and $\mathrm{C}_{\mathrm{Mx}}(\mathrm{c})$

\section{Conclusions}

The paper investigated aerodynamic loads on freight trains by means of wind tunnel tests. As expected significant differences have been found depending on the pattern of the containers. A significant result of this research is that the rollover moment on the wagon is increased if a fully loaded wagon follows an empty flat car. This pattern should be considered in the evaluation of the rollover risk. We intend to investigate more in detail this topic performing tests on a trainset model without the front engine: this new layout can reproduce a fully loaded vehicle following more than one empty flat car that has not been investigated in this study. The experimental data will be also used to investigate the aerodynamic stability of freight trains trough time-dependent multi-body simulations. 


\section{References}

[1] A. E. Beagles, D. I. Fletcher, "The aerodynamic of freight: approaches to save fuel by optimizing the utilization of container trains", Proceedings of the Institution of Mechanical Engineers, Part F: Journal of Rail and Rapid Transit, 14 May 2013.

[2] C. Baker, F. Cheli, A. Orellano, N. Paradot, C. Proppe, D. Rocchi, "Crosswind effects on road and rail vehicles" Vehicle System Dynamics, 47(8), 983$1022,2009$.

[3] F. Cheli, E. Di Gialleonardo, S. Melzi, "Numerical analysis of the curving performance of low flatcar wagons", International Journal of Heavy vehicle Systems, 18, 19-213, 2011.

[4] F. Cheli, R. Corradi, G. Tomasini, "Crosswind action on rail vehicles: A methodology for the estimation of the characteristic wind curves", J. Wind Eng. Ind. Aerodyn. 104-106, 248-255, 2012.

[5] Rail Accident Investigation Branch (RAIB), Detachment of containers from freight wagons near Cheddington and Hardendale, 1 March 2008.

[6] G. Tomasini, F. Cheli, "Admittance function to evaluate aerodynamic loads on vehicles: Experimental data and numerical model", Journal of Fluids and Structures 38, 92-106, 2013

http://dx.doi.org/10.1016/j.jfluidstructs.2012.12.009

[7] European Rail Agency. Technical Specification for Interoperability (TSI 232/2008) - Rolling Stock subsystem, 96/48/EC, 2008

[8] CEN 2010, EN14067-6. Railway applications - Aerodynamics. - Part 6: Cross wind. CEN, Brussels.

[9] F. Cheli, R. Corradi, D. Rocchi, G. Tomasini, E. Maestrini, "Wind tunnel tests on train scale models to investigate the effect of infrastructure scenario", Journal of Wind Engineering and Industrial Aerodynamics, 98, 353-362, 2010.

[10] H. Hemida, C. Baker, "Large-eddy simulation of the flow around a freight wagon subjected to a crosswind", Computers and fluids 39, 1944-1956, 2010.

[11] F. Cheli, S. Giappino, L. Rosa, G. Tomasini, M. Villani, "Experimental study on the aerodynamic forces on railway vehicles in presence of turbulence", J. Wind Eng. Ind. Aerodyn, 123, 311-316, 2013. 